\title{
Optimizing strategies to reduce alcohol consumption and relapses, improving abstinence in liver transplant recipients
}

\author{
Isabel Legaz $^{1 \# \wedge}$, Manuel Muro ${ }^{2 *} \wedge$ \\ ${ }^{1}$ Department of Legal and Forensic Medicine, Biomedical Research Institute (IMIB), Regional Campus of International Excellence "Campus Mare \\ Nostrum”, Faculty of Medicine, University of Murcia, Murcia, Spain; ${ }^{2}$ Immunology Service, Instituto Murciano de Investigación Biosanitaria (IMIB), \\ Hospital Clínico Universitario Virgen de la Arrixaca (HCUVA), Murcia, Spain \\ "These authors contributed equally to this work and should be considered as co-first authors. \\ Correspondence to: Dr. Isabel Legaz. Department of Legal and Forensic Medicine, Biomedical Research Institute (IMIB), Regional Campus of \\ International Excellence “Campus Mare Nostrum”, Faculty of Medicine, University of Murcia, 30110 Murcia, Spain. Email: isalegaz@um.es; \\ Dr. Manuel Muro. Immunology Service, Instituto Murciano de Investigación Biosanitaria (IMIB), Hospital Clínico Universitario Virgen de la \\ Arrixaca (HCUVA), Murcia, Spain. Email: manuel.muro@carm.es. \\ Comment on: Carrique L, Quance J, Tan A, et al. Results of Early Transplantation for Alcohol-Related Cirrhosis: Integrated Addiction Treatment \\ With Low Rate of Relapse. Gastroenterology 2021;161:1896-906.e2.
}

Submitted Dec 17, 2021. Accepted for publication Dec 28, 2021.

doi: $10.21037 / \mathrm{hbsn}-21-470$

View this article at: https://dx.doi.org/10.21037/hbsn-21-470

We have read with great attention and special interest the paper by Carrique and collaborators entitled: Results of Early Transplantation for Alcohol-Related Cirrhosis: Integrated Addiction Treatment with Low Rate of Relapse (1). In this prospective study, the authors initiated a pilot program to challenge the paradigm of the " 6 -month rule" of abstinence for patients with alcohol-related liver disease (ALD) requiring a transplant (2).

This study is the first trial in North America to admit patients with acute and chronic decompensated liver disease, regardless of abstinence length, and give comprehensive addiction treatment prior to and after liver transplantation (LT) to lower the risk of relapse. This interesting study involved an in-depth examination of patients' alcohol use, social support, and psychiatric comorbidity, as well as the provision of pre- and post-transplantation addiction treatment. In this sense, the authors report how their relapse prevention therapy was provided directly to all patients deemed to meet the program's inclusion criteria and how biomarker testing for alcohol was used pre and post-transplantation.

The final cohort informed in this study was 703 individuals fulfilling the program's criteria, 101 patients
(14\%) were listed for transplantation, and 44 (6.2\%) received transplants. The results of this study show that there were no significant differences in survival rates between those receiving transplants through the pilot program compared with a control group with more than six months of abstinence. Three patients returned to alcohol use during an average post-transplantation followup period of 339 days. Although the follow-up period was relatively brief, no post-transplant deaths were attributable to reverting to alcohol intake.

A recently published study on causes of death and survival in alcoholic cirrhosis patients undergoing LT (3) showed that at ten years, sepsis was the leading cause of death, accounting for 21.3 percent of all deaths, followed by graft failure $(18.9 \%)$ and multiorgan failure (15.6\%). Furthermore, the authors analyzed how pre-transplant clinical problems, such as viral infections and encephalopathy, influence the age at which the transplanted patient develops multiorgan failure. According to the authors, multiorgan failure is the primary cause of sudden death, with increased mortality over the first year following transplantation, followed by sepsis and graft failure.

Carrique et al. (1) show in their data that younger age

^ ORCID: Isabel Legaz, 0000-0002-1140-4313; Manuel Muro, 0000-0001-9987-0994. 
and lower Model for End-Stage Liver Disease (MELD) scores (27.11) at listing were associated with an increased likelihood of a return to alcohol use, and it was not found that length of abstinence was a predictor. This fact lowers MELD scores allowing for observation and intervention before transplantation, favoring the pilot program.

It should be noted that in a retrospective study with a cohort of 281 alcoholic cirrhosis patients undergoing LT, the MELD values obtained were usually even lower than those indicated by Carrique et al. (1), even taking into account the presence or absence of previous viral infection (mean: 14.3), but with similar mean ages (mean: 53.06 years) $(3,4)$. Therefore, the established pilot program Carrique et al. (1) could be extended to different cohorts of patients with different sociodemographic characteristics in order to see to what scientific point of view, with the data we have today, the generalized "6-month rule" of abstinence of alcohol makes sense, or in the case, on the contrary, a part of the patients is being harmed. One of the main advantages of our approach shown by the authors was the possibility of beginning the evaluation of a patient's transplant before completing the six months of abstinence, allowing the patient to benefit from the advancement of the intervention and, in some cases, avoid death.

On the other hand, it is essential to note that the authors found the frequency of men was higher than that of women in their study, as occurs in similar studies $(3,4)$. Differential behavior in alcohol consumption between different sexes would require that in the future, the authors analyze it differentially according to sex since necessary differential treatments could emerge that could be more efficiently adapted to the transplanted patient. Furthermore, higher consumption patterns have been reported in recent years, along with an increase in alcohol intake by women at extremely young ages, implying that liver illnesses will become more prevalent in the future (5-8).

The authors highlight the significance of having a social worker do a psychosocial assessment and intervention to potentially minimize issues that could make a person unsuitable for transplantation, such as community referrals for professional help or financial aid. This would be crucial in avoiding and preventing the structural inequities that exist in obtaining a referral for a transplant evaluation in the first place, regardless of your transplant reasons. While it is true that psychiatric and psychosocial intervention is a reality in many centers, although intervention efforts could be strengthened in these patients with risks of alcoholic relapse $(9,10)$. Family interventions contribute enormously to the fulfillment of medical indications and rearrange roles in the family system in transplantation conditions (9).

Age was an intriguing element to consider as well. Because the authors discovered that patients with a higher age had a higher chance of getting admitted into the program and that younger age was linked to a higher risk of recurrence, this last set of data could be explained in part by environmental factors, such as the presence of alcohol in the patients' settings $(11,12)$. It should be noted that, according to several studies, the average age of this sort of patient is around 53 years $(4,13)$. Perhaps this means an age that characterizes the transplant patient for alcoholic cirrhosis of other indications for transplantation (4) can benefit from the pilot study proposed by the authors who also use telemedicine to mitigate the barriers of distance or lack of resources on the part of the patient.

Furthermore, the authors (1) argue that biomarker testing was an invaluable tool throughout the many phases of the pilot program, as it can detect relapses in use and allow early involvement of the transplant team to address relapse and prevent damage to the graft. This is comparable to the findings of another study (14), which found that most of those who relapsed to alcohol use could restore abstinence and did not have a long-term relapse.

When assessing the risk of relapse in patients with ALD, the authors emphasize the significance of taking a wide range of variables into account. They believe that relying exclusively on the "6-month rule" to prohibit patients from receiving the transplant is insufficient and that adequate procedures can realistically lower the risk of relapse into alcoholism.

\section{Acknowledgments}

Funding: Our work was possible thanks to supporting from Instituto de Salud Carlos III (ISCIII), Spanish Ministry of Economy and Competitiveness. Grant Number P19/01194, and PI20/00050 and co-funding the European Union with the European Fund of Regional Development (FEDER) with the principle of "A manner to build Europe".

\section{Footnote}

Provenance and Peer Review: This article was commissioned by the editorial office, Hepatobiliary Surgery and Nutrition. The article did not undergo external peer review.

Conflicts of Interest: Both authors have completed the 
ICMJE uniform disclosure form (available at https://hbsn. amegroups.com/article/view/10.21037/hbsn-21-470/coif). The authors have no conflicts of interest to declare.

Ethical Statement: The authors are accountable for all aspects of the work in ensuring that questions related to the accuracy or integrity of any part of the work are appropriately investigated and resolved.

Open Access Statement: This is an Open Access article distributed in accordance with the Creative Commons Attribution-NonCommercial-NoDerivs 4.0 International License (CC BY-NC-ND 4.0), which permits the noncommercial replication and distribution of the article with the strict proviso that no changes or edits are made and the original work is properly cited (including links to both the formal publication through the relevant DOI and the license). See: https://creativecommons.org/licenses/by-nc-nd/4.0/.

\section{References}

1. Carrique L, Quance J, Tan A, et al. Results of Early Transplantation for Alcohol-Related Cirrhosis: Integrated Addiction Treatment With Low Rate of Relapse. Gastroenterology 2021;161:1896-906.e2.

2. Everhart JE, Beresford TP. Liver transplantation for alcoholic liver disease: a survey of transplantation programs in the United States. Liver Transpl Surg 1997;3:220-6.

3. Legaz I, Navarro Noguera E, Bolarín JM, et al. Patient Sex in the Setting of Liver Transplant in Alcoholic Liver Disease. Exp Clin Transplant 2019;17:355-62.

4. Legaz I, Navarro-Noguera E, Bolarín JM, et al. Epidemiology, Evolution, and Long-Term Survival of Alcoholic Cirrhosis Patients Submitted to Liver Transplantation in Southeastern Spain. Alcohol Clin Exp Res 2016;40:794-805.

Cite this article as: Legaz I, Muro M. Optimizing strategies to reduce alcohol consumption and relapses, improving abstinence in liver transplant recipients. HepatoBiliary Surg Nutr 2022;11(1):153-155. doi: 10.21037/hbsn-21-470
5. Manthey J, Shield KD, Rylett M, et al. Global alcohol exposure between 1990 and 2017 and forecasts until 2030: a modelling study. Lancet 2019;393:2493-502.

6. Rehm J, Rehm MX, Shield KD, et al. Alcohol consumption, alcohol dependence and related harms in Spain, and the effect of treatment-based interventions on alcohol dependence. Adicciones 2013;25:11-8.

7. Erol A, Karpyak VM. Sex and gender-related differences in alcohol use and its consequences: Contemporary knowledge and future research considerations. Drug Alcohol Depend 2015;156:1-13.

8. Sahlman P, Nissinen M, Pukkala E, et al. Incidence, survival and cause-specific mortality in alcoholic liver disease: a population-based cohort study. Scand J Gastroenterol 2016;51:961-6.

9. García-Alanís M, Toapanta-Yanchapaxi L, Vilatobá M, et al. Psychosocial evaluation for liver transplantation: A brief guide for gastroenterologists. Rev Gastroenterol Mex (Engl Ed) 2021;86:172-87.

10. Octavio Rojas G, Vania Krauskopf P, Juan Agustín Umaña M, et al. Intervención psiquiátrica en programa de trasplantes. Rev Médica Clínica Las Condes 2010;21:286-92.

11. Dawson DA, Goldstein RB, Grant BF. Rates and correlates of relapse among individuals in remission from DSM-IV alcohol dependence: a 3-year follow-up. Alcohol Clin Exp Res 2007;31:2036-45.

12. Karim Z, Intaraprasong P, Scudamore CH, et al. Predictors of relapse to significant alcohol drinking after liver transplantation. Can J Gastroenterol 2010;24:245-50.

13. Burra P, Senzolo M, Adam R, et al. Liver transplantation for alcoholic liver disease in Europe: a study from the ELTR (European Liver Transplant Registry). Am J Transplant 2010;10:138-48.

14. Lee BP, Chen PH, Haugen C, et al. Three-year Results of a Pilot Program in Early Liver Transplantation for Severe Alcoholic Hepatitis. Ann Surg 2017;265:20-9. 